\title{
A DESIGN OPTIMIZATION STUDY FOR THE DIE DIMENSIONING USING THE LOCKING NUT FOLDING SIMULATION
}

\author{
BOZKURT Ülüver ${ }^{1}$, KACAR İlyas $^{2 *}$ \\ ${ }^{1}$ Engineering Faculty, Niğde Ömer Halisdemir University, Department of Mechanical Engineering, Niğde, \\ Turkey,e-mail:uluverbzkrt@gmail.com \\ ${ }^{2}$ Engineering Faculty, Niğde Ömer Halisdemir University, Department of Mechatronics Engineering, Niğde, \\ Turkey,e-mail: ikacar@ohu.edu.tr
}

\begin{abstract}
An inverse analysis based on optimization process is performed to determine die curvatures for a locking nut's flange folding process which has highly nonlinear material behaviour. The nut material is AISI C1040 steel. The ring material is polyamide 6. The Chaboche's nonlinear kinematic hardening rule is combined with bilinear isotropic hardening model as a hardening rule for the plasticity model combined with associated flow rule and von Mises yield criterion. The inverse analysis is applied to determine the curvatures by using genetic algorithm optimization method based on dimensional accuracy. The optimum mould curvatures are determined. So a comprehensive methodology is presented for determination of curvatures.
\end{abstract}

KEYWORDS: Plastic deformation, inverse analysis, optimization, plasticity model, locking nut.

\section{Introduction}

Nut and bolts are used for connection. They loosen when the vibration level is high under severe working conditions. To avoid from loosening, lock nuts are designed. They provide blocking the connection against loosening. They have better performance than other nuts. There are few kinds of lock nuts and one of them is "nylock nut" where a nylon ring is inserted inside the nest in the nut and it locks the connection by providing higher frictional coefficient. Nylock nuts are inserted by bending of the nut's flange. The bending includes highly plastic flow. Less or more folding causes to loosen the connection [1,2]. Avoiding less or more folding is a problematic case for nylock nut manufacturers. Figure 1 shows a nylon insertion and the flange folding processes.

The concept of flow in the material is a term used to describe the plastic behaviour of materials in solid body mechanics. Plasticity theories are used to determine the amount of plastic deformation $\left(\varepsilon^{p}\right)$ in any deformation process.

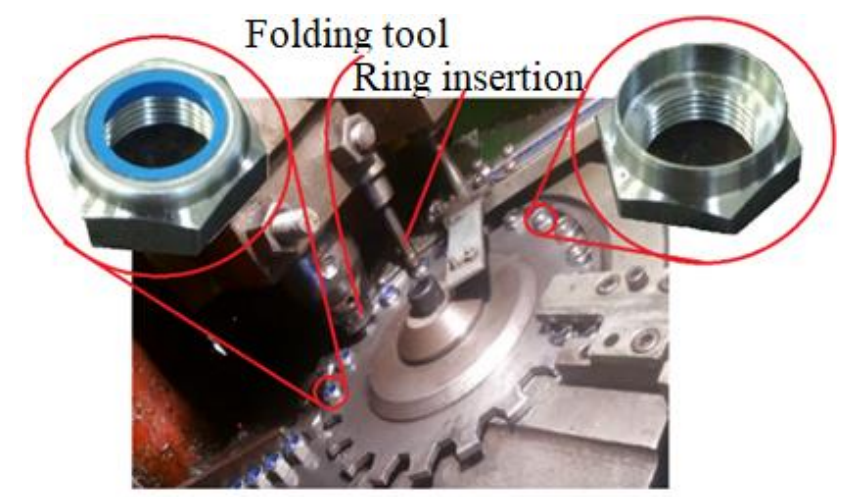

Fig. 1. The nylon insertion and flange folding processes 
Total strain in a body is decomposed as a summation of elastic $\left(\varepsilon^{e}\right)$ and plastic $\left(\varepsilon^{p}\right)$ strain. The elastic strain can be calculated by elastic or hyper elastic constitutive equations. However, the determination of the plastic strain requires a flow criterion, a hardening rule and a flow rule for a computer simulation.

To achieve a successful manufacturing of the nylocks, the die grove shape is so important. Especially its curvatures are main actors to control the plastic flow direction during the presswork. Uncontrolled plastic flow leads to lack/more folding resulting in loosening in the connection or crack on the ring member. A designer has to consider the plastic flow when calculating the die curvatures and dimensions. There is no a regular calculation method to be applied on all deformation types. Thus, each one of the deformation processes has to be taken individually. One of the calculation method is to use inverse approach based on the optimization method.

Inverse analysis is a general method applied in engineering [3,4]. Genetic algorithm (GA) and particle swarm method are well-known optimization methods [5-11]. Up to now, any systematic method for the deformation simulations has not been developed yet.

In this study, the inverse analysis with GA optimization is used for determination of the best dimensions of the folding tools to catch optimum folding conditions by using a finite element (FE) simulation of the folding process on the lock nut. As a hardening rule, a combined hardening rule including Chaboche's kinematic hardening (CHAB) and bilinear isotropic hardening rule (BISO) is used. Final diameter and height of the locking nut measurements are compared with those obtained from optimized model. So a comprehensive methodology is presented for mold dimension determination.

\section{Preliminary Design}

In Figure 2, an initial tooling design and its FE model are given. FE simulations are used for optimization.

Two lines (Line-1 and Line-2) and two radius (Curvature-1 and Curvature-2) are our scope as the design variables. Any change in the length of the lines will change the radius and center location of the curvatures softly and slowly. Thus, excessive and physically impossible fillet and radius are avoided. Their linear behavior also will provide easiness in the die manufacturing.

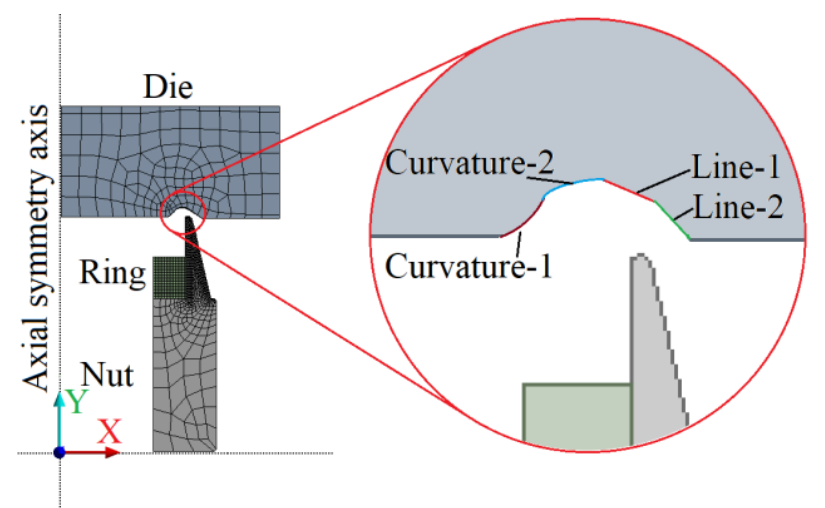

Fig. 2. Preliminary design and its axial symmetric FE model

\subsection{Chemical Composition}

The nut and ring materials are AISI1040 steel and polyamide 6 (PA6) respectively. Chemical compositions are given in Table 1. 
Table 1. Chemical composition of the AISI1040 and PA6 (weight\%)

\begin{tabular}{|c|c|c|c|c|c|}
\hline \multirow{4}{*}{ 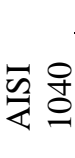 } & $\mathrm{C}$ & $\mathrm{Mn}$ & $\mathrm{Si}$ & $S$ & $\mathrm{P}$ \\
\hline & 0.37 & 0.7 & 0.34 & 0.005 & 0.015 \\
\hline & $\mathrm{Ni}$ & $\mathrm{Cr}$ & $\mathrm{Cu}$ & $\mathrm{N}$ & $\mathrm{Fe}$ \\
\hline & 0.014 & 0.018 & 0.03 & 0.07 & balance \\
\hline \multirow{2}{*}{$\underset{1}{0}$} & $\mathrm{C}$ & $\mathrm{O}$ & $\mathrm{N}$ & $\mathrm{P}$ & $\mathrm{Si}$ \\
\hline & 52.36 & 35.50 & 7.74 & 3.45 & 0.95 \\
\hline
\end{tabular}

\subsection{Mechanical Characterizations}

The simulation needs the mechanical properties of the materials. Linear elastic material properties used in this study are given in Table 2 [12].

Table 2. Linear material properties [12]

\begin{tabular}{lll}
\hline & \multicolumn{1}{c}{ AISI1040 } & \multicolumn{1}{c}{ PA6 } \\
\hline Density & $7.85 \mathrm{gr} / \mathrm{cm}^{3}$ & $0.952 \mathrm{gr} / \mathrm{cm}^{3}$ \\
Elasticity modulus & $207 \mathrm{GPa}$ & $1100 \mathrm{MPa}$ \\
Poisson ratio & 0.28 & 0.42 \\
Yield point, $Y S$ & $415 \mathrm{MPa}$ & $26.2 \mathrm{MPa}$ \\
Maximum stress & $651.84 \mathrm{MPa}$ & $33 \mathrm{MPa}$ \\
Tangent modulus, $T M$ & $2014.21 \mathrm{MPa}$ & $1070 \mathrm{MPa}$ \\
$r_{0}$ & 1.11 & -- \\
$r_{45}$ & 1.01 & -- \\
$r_{90}$ & 1.27 & -- \\
\hline
\end{tabular}

\subsection{Hardening Rule Parameters}

During any plastic deformation process, hardening or softening occurs due to locking or releasing of dislocation movements when yield starts. While the isotropic hardening rule governs the evolution of the expansion or contraction of the yield surface, the kinematic hardening rule controls the evolution of the "back stress" $\alpha_{i j}$ which causes the center point of the yield surface to translate. Do not confuse the isotropic rule to "isotropic material".

A combined hardening model consisting of an isotropic rule and a kinematic rule is used in this study. Its parameters are given in Table 3 [13] and will be explained in subsequent sections in detail.

Table 3. The combined hardening model parameters [13]

\begin{tabular}{ll}
\hline Parameters & Value \\
\hline$Y S(\mathrm{MPa})$ & 4000 \\
$T M(\mathrm{MPa})$ & 300 \\
$C_{1}(\mathrm{MPa})$ & 40931.4 \\
$\gamma_{1}$ & 18207.5 \\
$C_{2}(\mathrm{MPa})$ & 18734.8 \\
$\gamma_{2}$ & 18072.1 \\
$C_{3}(\mathrm{MPa})$ & 1000 \\
$\gamma_{3}$ & 30000 \\
\hline
\end{tabular}

\section{Constitutive Equations for FE Simulations}

In the simulation, the material's nonlinear mechanical behavior is established by means of a constitutive model. The von Mises yield criterion is used for the constitutive model [14]. The hardening rule is embedded inside the yield criterion. 


\subsection{Yield Criteria}

A yield criterion provides an equivalent stress value for a stress state. A general comparison formula is given in $\mathrm{Eq}(1)$.

$$
\bar{\sigma}\left(\sigma_{i j}\right)-\sigma_{0}=0
$$

where $\sigma_{0}$ is initial size of the yield surface. $\bar{\sigma}$ is a scalar equivalent of the stress state. General equation of the Von Mises yield function is given in Eq. (2).

$$
\bar{\sigma}^{2}\left(\sigma_{1}, \sigma_{2}, \sigma_{3}\right)=\frac{\left|\sigma_{1}-\sigma_{2}\right|^{2}+\left|\sigma_{2}-\sigma_{3}\right|^{2}+\left|\sigma_{3}-\sigma_{1}\right|^{2}}{2}
$$

where $\sigma_{1}, \sigma_{2}, \sigma_{3}$ are principal stresses.

\subsection{Hardening Rule}

Isotropic and kinematic terms can be added to the comparison equation as in Eq. (3). It includes both rules.

$$
\bar{\sigma}\left(\sigma_{i j}-\alpha_{i j}\right)-\sigma(h)=0
$$

where $\sigma(h)$ is the isotropic rule, $\alpha_{i j}$ is the back stress term which comes from kinematic rule. CHAB's $\alpha_{i j}$ function is given in Equations $(4,5)[15,16]$.

$$
\sigma(h)=Y S+T M\left(\varepsilon^{p}\right)
$$

where $Y S$ is yield strength, $T M$ is the tangent modulus, $\varepsilon^{p}$ shows the effective plastic strain increment.

$$
\begin{aligned}
& \left(\dot{\alpha}_{i j}\right)_{m}=\underbrace{\frac{2}{3} C_{m} \dot{\varepsilon}_{i j}^{p}}_{\text {linear term }}-\underbrace{\gamma_{m}\left(\alpha_{i j}\right)_{m} \sqrt{\frac{2}{3} \dot{\varepsilon}_{i j}^{p}: \dot{\varepsilon}_{i j}^{p}}}_{\begin{array}{c}
\text { the plastic strain range } \\
\text { memorization term }
\end{array}}+\underbrace{\frac{1}{C_{m}} \frac{\partial C_{m}}{\partial T}\left(\alpha_{i j}\right)_{m} \dot{T}}_{\text {heat rate term }} \\
& \text { where } m=1,2, \ldots n
\end{aligned}
$$

where $n$ is the total term number, $T$ is the temperature. $C_{m}$ is the hardening module. It also refers to the saturation rate. $\gamma_{m}$ is the decrease rate. $\dot{\varepsilon}_{i j}^{p}$ is the accumulated plastic strain rate and will be provided by a flow rule. All of these parameters can be determined by a nonlinear regression process.

\subsection{Flow Rule}

A flow rule gives the relationship between the stress and the plastic deformation $\left(\varepsilon_{i j}^{p}\right)$ by $d \varepsilon_{i j}^{p}=d \lambda \frac{\partial f}{\partial \sigma_{i j}}$ where $\lambda$ is the plastic multiplier, $d \varepsilon_{i j}^{p}$ or $\dot{\varepsilon}_{i j}^{p}$ is the cumulative amount of plastic deformation, and $f$ is a scalar function called "plastic potential". If $f=\bar{\sigma}$, the rule is called "associated flow rule". In this study, the yield criterion's function is taken as a plastic potential function.

\section{$4 \quad$ Simulation and Optimization}

\subsection{Folding Simulations}

Instead of a 3D model, an axial symmetric 2D model seen in Figure 3 is simulated. The cylindrical coordinate system $(x, \theta, z)$ is located at the centre point of the nut. While the axial symmetry axis is located on the $y$ direction, the radial direction corresponds to the $x$ direction. 
The cross-section of the geometry is located at the positive side at $x$ direction considering radial dimensions. No thread is added on the FE model of the nut. Its hexagonal body is assumed cylindrical. Permanent deformation happens only at its flange.

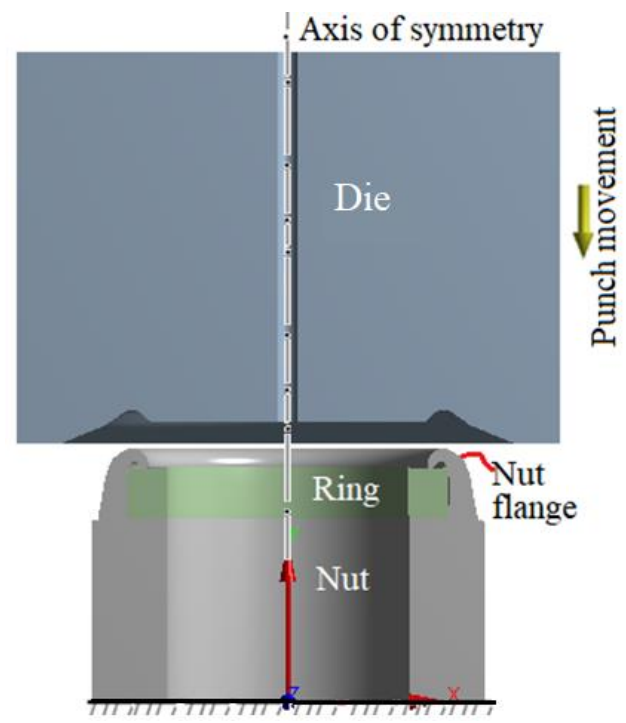

Fig. 3. An axial symmetric model of the folding process

Coulomb friction model with 0.25 coefficient is used to model the friction between die and the nut. While the die is modeled as rigid body, the nut and ring are modeled as flexible bodies by assigning AISI 1040 and PA6 materials respectively. Elastic properties in Table 2 and inelastic properties in Table 3 are used as engineering data. The nut's bottom edge is fix supported. Similarly, bottom side of the ring is fixed to its nest. The punch moves just at its axial direction. Some vertical gap between the punch and the nut's flange is set in the beginning. 14027 elements were enough for converging in the results. This simulation is used for the optimization.

\subsection{Optimization}

Sequential two curvatures and two lines are selected as the design variables for optimization. Their radius and length are parameterized. Initial parameters to be used as the starting points and their lower and upper limits are listed in Table 4. 10,000 design of experiment (DOE) points are created between these limits.

Table 4. Lower and upper limits of the design variables

\begin{tabular}{llll}
\hline Design variables & $\begin{array}{l}\text { Lower } \\
(\mathbf{m m})\end{array}$ & $\begin{array}{l}\text { Upper } \\
(\mathbf{m m})\end{array}$ & $\begin{array}{l}\text { Initial } \\
(\mathbf{m m})\end{array}$ \\
\hline Radius of curvature-1 & 0.1 & 4 & 1 \\
Radius of curvature-2 & 0.1 & 4 & 2 \\
Length of line-1 & 0.1 & 4 & 2 \\
Length of line-2 & 0.1 & 4 & 3 \\
\hline
\end{tabular}

The optimizations are performed on the FE model of the folding process. The folded height and diameter of the flange are predicted as output variables. The applied goals and constraints in the optimization are;

- the target for the diameter has been specified between $23.5 \mathrm{~mm}$ to $24 \mathrm{~mm}$,

- the target for the nylock nut's height has been specified between $18.5 \mathrm{~mm}$ to $19 \mathrm{~mm}$ after folding,

Experimental measurements before and after folding for M20x1.5 are listed in Table 5. 
Table 5. Measurements before and after folding

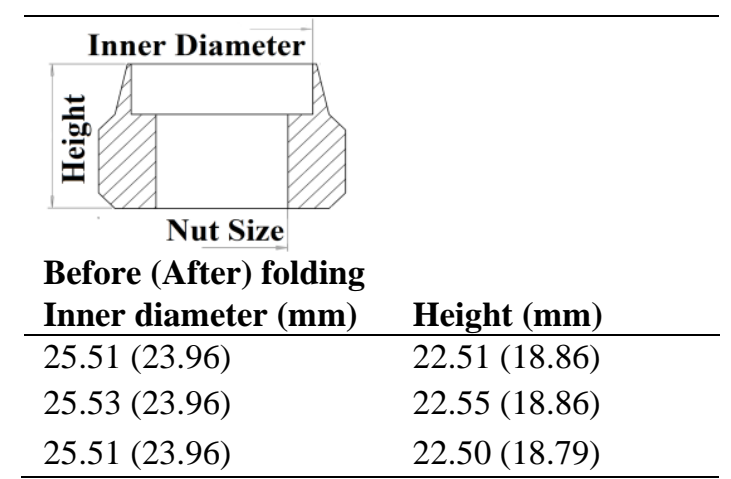

Our goal is to minimize the difference between the measured and predicted results. By considering those constrains, the values which minimize the difference are selected as optimum values. Genetic algorithm (GA) method is used as the optimization method. Its parameters are given in Table 6.

Table 6. GA parameters used in the study

\begin{tabular}{lc}
\hline Parameters & Value \\
\hline Estimated number of evaluation & 2000 \\
Number of initial samples & 100 \\
Number of samples per iteration & 100 \\
Maximum allowable Pareto percentage & $70 \%$ \\
Convergence stability percentage & $2 \%$ \\
Maximum number of iterations & 20 \\
\hline
\end{tabular}

The best parameters will be the optimum values which lead the simulation results to (almost) match the experimental results. The goal function is set $0.5 \%$ as the convergence stability criterion. Although maximum iterations are limited to 1000 as a stopping criterion for the optimization process, the most probable and physically possible points are found within 8 iterations. The convergence status during the optimization process is given in Figure 4. 13662 evaluations are performed for the folding simulations.

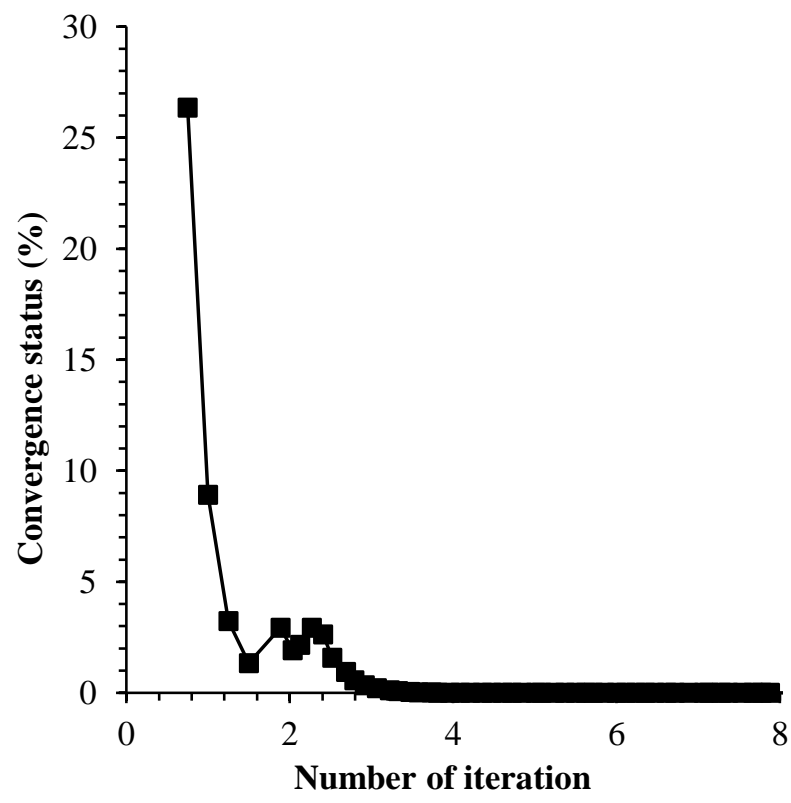

Fig. 4. The convergence of the goal function during iterations of the optimization process 


\section{$5 \quad$ Results and Discussion}

\section{$5.1 \quad$ The Optima}

Table 7 gives the optimum dimensions. Corresponding shape is given in Figure 5 when optimum dimensions are applied. Line-1 shortens while Line-2 extends. This leads the curvature- 2 to increase. Thus, contact line between flange and die increases. As a result, bending angle will increase. So excessive element distortion is eliminated. It helps the solutions convergence.

Table 7. The optima of the design variables

\begin{tabular}{ll}
\hline Design variables & The optima (mm) \\
\hline Radius of curvature-1 & 0.5 \\
Radius of curvature-2 & 2.3879 \\
Length of line-1 & 1.3542 \\
Length of line-2 & 3.6487 \\
\hline
\end{tabular}

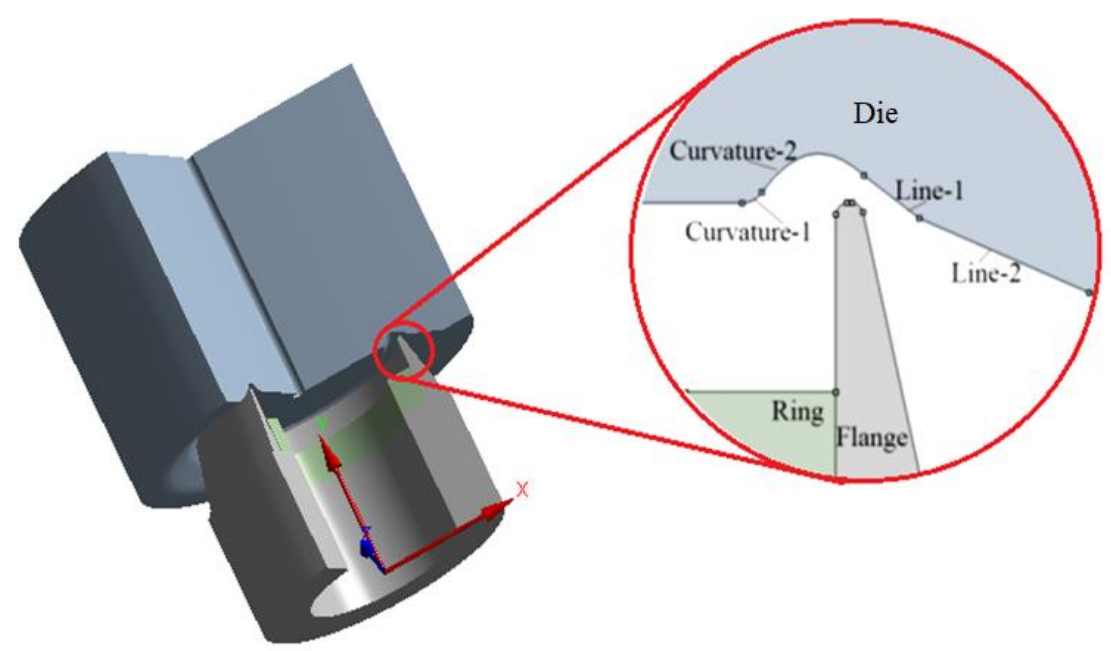

Fig. 5. The optimum die shape when optimum dimensions are applied

\subsection{Equivalent Stress and Deformation Distributions}

Figure 6 shows the Von Mises stress distribution on the nut body at the last sub step of the last step of the simulation, when the optima is used. Stress increases up to $456 \mathrm{MPa}$ due to hardening, as expected. The combined hardening model has the ability to represent the hardening.

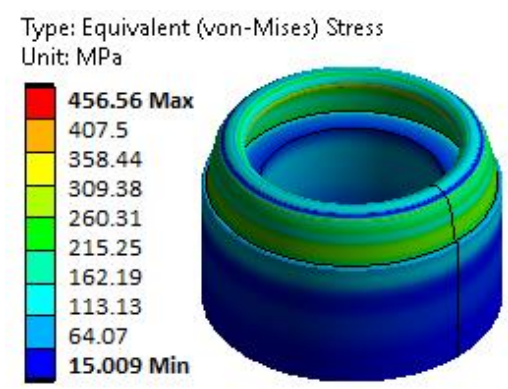

Fig. 6. Von-Mises stress distribution on the nut body

Figure 7 gives the Von Mises stress distribution on the ring at the last sub step of the last step of the simulation. Stress increases up to $8 \mathrm{MPa}$, which is under the material's yield point 26.2 MPa. 


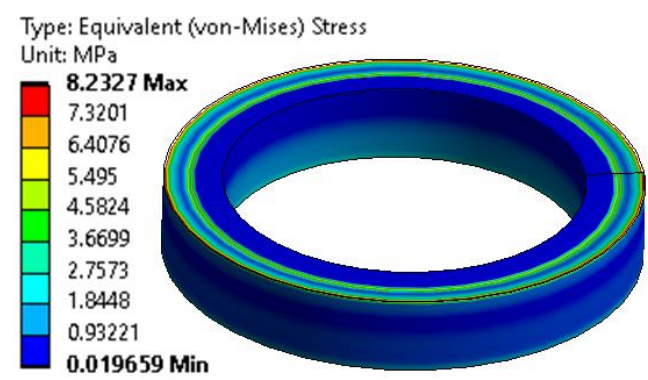

Fig. 7. Von-Mises stress distribution on the ring

Figure 8 exhibits the total deformation on the nut body. The maximum deformation is $3.9549 \mathrm{~mm}$ and seen on the flange tip because the punch touches its tip first and bends the flange. In addition, it is seen that the nut body does not undergo any plastic deformation as seen.

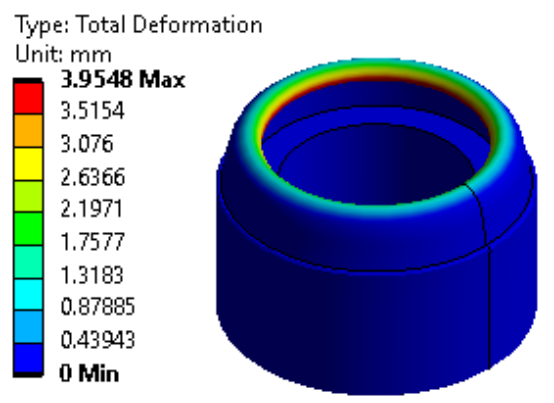

Fig. 8. Total deformation on the nut body

Figure 9 gives the total deformation on the ring. The maximum deformation is $0.1584 \mathrm{~mm}$ and seen on the contact zone between flange tip and the ring surface. When the flange tip is removed after folding, a grave occurs at the location where the flange tip touches due to its elastic deformation.

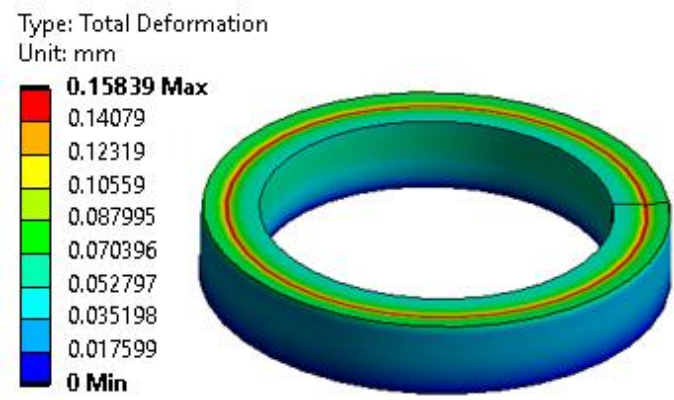

Fig. 9. Total deformation on the ring

Figure 10 and 11 give the height and diameter of the nut body after deformation. The desired height and diameter as in Table 6 are achieved when the optima are used. 


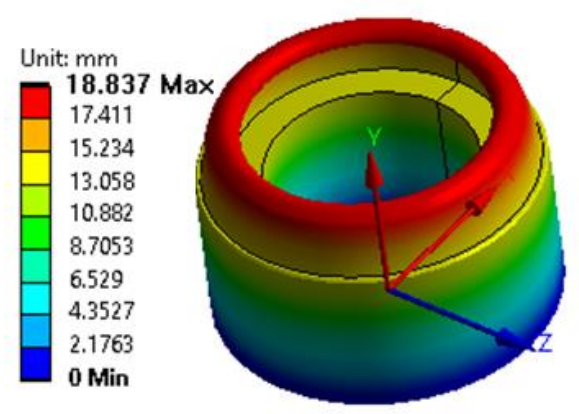

Fig. 10. Total height of the nut body after deformation

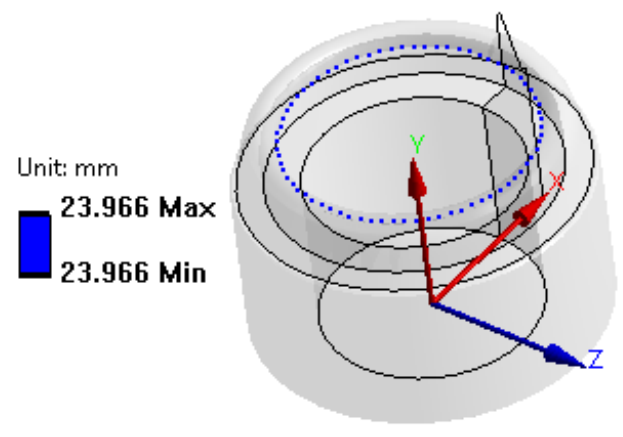

Fig. 11. Total diameter of the nut flange tip after deformation

\subsection{Validations}

A mesh independency vs. convergence analysis is performed and given in Table 8 .

Table 8. A mesh independency analysis

\begin{tabular}{lll}
\hline $\begin{array}{l}\text { Number of } \\
\text { elements }\end{array}$ & $\begin{array}{l}\text { Change in } \\
\text { diameter results }(\%)\end{array}$ & $\begin{array}{l}\text { ine } \\
\text { time }\end{array}$ \\
\hline 1472 & - & $57 \mathrm{~s}$ \\
2219 & 3.21845 & $1 \mathrm{~m} \mathrm{49} \mathrm{s}$ \\
3422 & 0.203045 & $2 \mathrm{~m} \mathrm{12} \mathrm{s}$ \\
5368 & 0.0499415 & $4 \mathrm{~m} \mathrm{18} \mathrm{s}$ \\
14027 & 0.0058335 & $5 \mathrm{~m} \mathrm{52} \mathrm{s}$ \\
29263 & 0.0056665 & $23 \mathrm{~m} \mathrm{16} \mathrm{s}$ \\
37279 & 0.0056445 & $45 \mathrm{~m} \mathrm{58} \mathrm{s}$ \\
\hline
\end{tabular}

When the model with 14027 elements is used, the change on the results will be under $0.005 \%$. During optimization, 8753 DOE points are converged. The others are not converged due to the physically impossible shape in the DOE point. It took 35 days by a computer having $8 \mathrm{~GB}$ RAM and a quad core CPU with $3.40 \mathrm{GHz}$.

The validations are performed on the nut, M24x1. Although the nut size changes, its flange size does not changed. Thus, the same die is used for its folding, too. The simulated and experimentally obtained diameter, height results are seen in Table 9. They are compared with the experimental means.

Table 9. Validation of the verified models on the nut M24x1.5

\begin{tabular}{llll}
\hline Output & Simulated & Measured & Error $(\%)$ \\
\hline Diameter $(\mathrm{mm})$ & 30.81 & 30.04 & 2.56 \\
Height $(\mathrm{mm})$ & 25.74 & 25.05 & 2.75 \\
\hline
\end{tabular}




\subsection{Discussion}

The percent relative error between simulated and experimentally measured outputs is up to $2.75 \%$ which is lower than $4 \%$ in [17], and $3 \%$ in [18].

The issue of the die design is of great importance especially in the manufacturing industry. The time consumption and trial-error costs make this issue expensive. Die dimension determination still involves uncertainties, as experience is limited and new experiments are not cost efficient.

A folding simulation driven by the design approach is performed successfully by means of a parametric modeling and optimization $[8-10,12,19]$ with the genetic algorithm method $[4$, $5,7-9]$. The importance of this study is that it eliminates the trial and error costs and allows a fast and economical design for a new nylocks. A previous study demonstrated that optimization methods allowed model parameter calibration, error minimization, design improvement [3]. This report is consistent with our findings that mold dimensions are optimized to minimize the nuts dimensional tolerances. It is understood that folding simulation based design optimization approach can be used in mold design.

Most typical deficiency in optimization process is the constitutive model to be used. It directly affects the results and may cause to fail in the solution convergence. So the process depends on the material model strictly.

\section{CONCLUSION}

A genetic algorithm based optimization process is performed to optimize die dimensions for a locking nut's flange folding process. The optimum die curvatures are determined and verified. Also stress and deformation distribution results are given. So the following inferences are concluded.

(1) Inverse analysis can be used to determine optimum die dimensions.

(2) The combined hardening rule which is composed of BISO and CHAB represents well the plastics flow seen during folding deformation.

(3) Diameter and height can be used as output for optimization. Thus, simple measurements will be enough for optimization and its validations. It makes the method more useful.

Optimization and design exploration lead to better designs. It shortens development times and reduce design cycles. It increase knowledge about product's behavior.

\section{REFERENCES}

[1] Bhattacharya, A. S., Sen, A., Das, S. "An investigation on the anti-loosening characteristics of threaded fasteners under vibratory conditions", Mechanism and Machine Theory, pp. 1215 - 1225, 2010.

[2] Gong, H., Liu, J., Ding, X. "Effect of ramp angle on the anti-loosening ability of wedge nylock nuts under vibration", Journal of Mechanical Design, Transactions of the ASME 140 (7), 2018.

[3] Broggiato G.B., Campana F., Cortese L. "The Chaboche nonlinear kinematic hardening model: calibration methodology and validation”, 43 (2), pp. 115 - 124, 2008.

[4] Franulović M., Basan R., Prebil I. "Genetic algorithm in material model parameters' identification for low-cycle fatigue" 45 (2), pp. 505 - 510, 2009. 
[5] Mahmoudi A.H., Pezeshki-Najafabadi S.M., Badnava H. "Parameter determination of Chaboche kinematic hardening model using a multi objective Genetic Algorithm", Computational Materials Science 50 (3), pp. 1114 - 1122, 2011. DOI: 10.1016/j.commatsci.2010.11.010

[6] Mahmoudi A.H., Badnava H., Pezeshki-Najafabadi S. M. "An application of Chaboche model to predict uniaxial and multiaxial ratcheting", Procedia Engineering 10, pp. 1924 - 1929, 2011. DOI: 10.1016/j.proeng.2011.04.319

[7] Badnava H., Pezeshki S. M., Fallah Nejad K., Farhoudi H. R. "Determination of combined hardening material parameters under strain controlled cyclic loading by using the genetic algorithm method”, Journal of Mechanical Science and Technology 26 (10), pp. 3067 - 3072, 2012. DOI: 10.1007/s12206-012-0837-1

[8] Chaparro, B. M., Thuillier, S., Menezes, L. F., Manach, P. Y., Fernandes, J. V. "Material parameters identification: Gradient-based, genetic and hybrid optimization algorithms", Computational Materials Science 44 (2), pp. 339 - 346, 2008. DOI: 10.1016/j.commatsci.2008.03.028

[9] Nath, A., Ray, K. K., Barai, S.V. "Evaluation of ratcheting behaviour in cyclically stable steels through use of a combined kinematic-isotropic hardening rule and a genetic algorithm optimization technique", International Journal of Mechanical Sciences 152, pp. 138 - 150, 2011. DOI: 10.1016/j.ijmecsci.2018.12.047

[10] Shojaeefard M. H., Behnagh R. A., Akbari M., Givi M. K. B., Farhani F. "Modelling and Pareto optimization of mechanical properties of friction stir welded AA7075/AA5083 butt joints using neural network and particle swarm algorithm", Material \& Design 44, pp. 190 - 198, 2013. DOI: 10.1016/j.matdes.2012.07.025

[11] Moslemi N., Gol Zardian M., Ayob A., Redzuan N., Rhee S. "Evaluation of sensitivity and calibration of the chaboche kinematic hardening model parameters for numerical ratcheting simulation", Appl. Sci. 9 (12), 2578, 2019. DOI: 10.3390/app9122578

[12] Parida A. K., Soren S., Jha R. N., Sadhukhan S. "Formability of Al-killed AISI 1040 medium carbon steel for cylindrical cup formation", ISIJ International, pp. $610-618$, 2016.

[13] Agius D., Kajtaz M., Kourousis K. I., Wallbrink C., Hu W. "Optimising the multiplicative AF model parameters for AA7075 cyclic plasticity and fatigue simulation", Aircraft Engineering and Aerospace Technology 90 (2), pp. 251 - 260, 2018.

[14] Mises, R.V. "Mechanics of solid bodies in the plastically-deformable state", Mathematisch-physikalische Klasse 1, pp. 582 - 592, 1913.

[15] Qu, F., Z. Jiang, H. Lu "Effect of Mesh on Springback in 3D Finite Element Analysis of Flexible Microrolling”, Journal of Applied Mathematics, pp. 147 - 160, 2015.

[16] Tong, J., Zhan, Z. L., Vermeulen, B. "Modelling of cyclic plasticity and viscoplasticity of a nickel-based alloy using Chaboche constitutive equations", International Journal of Fatigue 26 (8), pp. 829 - 837, 2004.

[17] Ramezansefat, H., Shahbeyk, S. "The Chaboche hardening rule: A re-evaluation of calibration procedures and a modified rule with an evolving material parameter", Mechanics Research Communications 69, pp. $150-158,2015$. DOI: 10.1016/j.mechrescom.2015.08.003 
[18] Hassan, T., Kyriakides, S. "Ratcheting in cyclic plasticity, part i: Uniaxial behaviour", International Journal of Plasticity 8 (1), pp. 91 - 116, 1992. DOI: 10.1016/07496419(92)90040-J

[19] MD Zahid H., Moshiur R., MD. Samiul R., Limon S., Souvik R. "Design optimization of stair climbing cart for developing countries", Strojnícky časopis - Journal of Mechanical Engineering 70 (1), pp.1 - 16, 2020. DOI: 10.2478/scjme-2020-0001 